\title{
A experiência de um grupo de dança com atividades criativas durante a pandemia
}

The experience of a dance group doing creative activities during the pandemic

Elida Fogliarini Capelatto', Rosane Beltrão da Cunha Carvalho²

${ }^{1}$ Academia Kraft Ballet, Campinas, Brasil

2 Instituto Federal de Educação, Ciência e Tecnologia de São Paulo (IFSP), Campinas, Brasil

\section{HISTÓRICO DO ARTIGO}

Recebido: 26 fevereiro 2021

Revisado: 30 junho 2021

Aprovado: 01 novembro 2021

\section{PALAVRAS-CHAVE:}

Dança; Mulheres;

Pandemia.

\section{KEYWORDS:}

Dance; Women;

Pandemic.

PUBLICADO:

01 janeiro 2022

\section{RESUMO}

INTRODUÇÃO: Este é um relato de experiência de um grupo de dança durante o isolamento social imposto pela pandemia de COVID-19. Com a interrupção do funcionamento das escolas de dança, o grupo precisou se reinventar.

OBJETIVO: Relatar a experiência de um grupo de dança que existe há mais de 15 anos, composto por mulheres na meia idade, durante a pandemia em 2020, quando foram proporcionadas algumas atividades relacionadas à dança, de forma produtiva e as ações criativas para reforçar o relacionamento entre as participantes.

MÉTODOS: Foram lançados vários desafios de atividades para acontecerem na quarentena, inicialmente de forma despretensiosa, mas que acabaram dando muito sentido a esse tempo de isolamento vivido no ano de 2020.

RESULTADOS: Ao todo foram 12 diferentes atividades realizadas com muita criatividade, empolgação e engajamento, que contribuíram para manter as atividades de dança, a amizade, a descontração e a alegria desse grupo. Também foram produzidas duas coreografias no período de ocorrência das aulas no período presencial e online.

CONCLUSÃO: Considerando todas as dificuldades enfrentadas, pode-se inferir que esse foi um ano muito produtivo e de muita proximidade entre as integrantes do grupo, apesar de distantes fisicamente. Ao final, percebeu-se que muito foi realizado. De certa forma, talvez até mais do que se estivéssemos vivendo num ano "normal".

\section{ABSTRACT}

BACKGROUND: This is an account of the experience of a dance group during the social isolation imposed by the COVID-19 pandemic. With the disruption of the dance classes, the group had to reinvent itself.

OBJECTIVE: To report the experience of a middle-aged women dance group that was formed over 15 years ago during the 2020 pandemic, showing how the group managed to productively maintain their dance related activities and come up with creative actions to strengthen the relationship between the participants.

METHODS: Several challenges were unpretentiously launched and done during the quarantine which ended up giving a lot of meaning to this time of isolation experienced in 2020.

RESULTS: There were 12 different activities that were carried out with great creativity, excitement and engagement, which contributed to maintaining the dance activities, friendship, relaxation and joy of the group. In addition, two dance routines were made and rehearsed during the online and in person classes.

CONCLUSION: Considering all the difficulties that came along with 2020, we can infer that this was a very productive year and one of great proximity between the members of the group, despite being physically distant. Ultimately it seems like a lot has been accomplished. In a way, maybe even more than if we were living a "normal" year. 


\section{INTRODUÇÃO}

\section{0 cenário}

Em 11 de março de 2020 a Organização Mundial da Saúde (OMS) anunciou que a COVID-19, doença causada pelo novo coronavírus, era então considerada como uma pandemia (OPAS, 2020). Pouco tempo depois, estados e municípios no Brasil tomaram medidas de isolamento social, fechamento de comércio não essencial, academias e escolas, dentre outras medidas. Todas essas mudanças aconteceram num curto espaço de tempo e, repentinamente, as rotinas foram alteradas drasticamente.

Parentes e amigos deixaram de se encontrar, a não ser virtualmente. As ferramentas tecnológicas tiveram que ser usadas, mesmo por quem não tinha tanto interesse ou intimidade com elas. Aulas, palestras e consultas passaram a ser online. As escolas precisaram se reinventar, assim como os professores e estudantes, para se adaptarem a uma nova realidade. Além do isolamento, outros fatores sociais causaram muita preocupação e sofrimento, de forma individual ou coletiva, como a crise econômica, o medo de adoecer, a incerteza causada pelas ações governamentais para a segurança e proteção à vida, a insegurança em relação ao trabalho e ao emprego, a tragédia instalada com o alto número de mortes, o luto...

Essas são algumas das dificuldades enfrentadas, em maior ou menor grau, nesse período de afastamento e tentativa de controle da pandemia. Todos esses enfrentamentos e sofrimentos têm potencial para afetar a saúde mental das pessoas, podendo levar ao adoecimento e transtornos (BARREIRA; TELLES, FILGUEIRAS, 2020). No Brasil houve aumento significativo de ansiedade, depressão e estresse agudo durante a pandemia (FILGUEIRAS; STULTS-KOLEHMAINEN, 2020).

Embora o foco do isolamento social seja a proteção da saúde física, tem sido percebido que a saúde mental da população também tem sido abalada. Muitos estudiosos têm se debruçado em estudar e discutir estratégias de enfrentamento para fazer com que o cenário se torne menos adoecedor (OLIVEIRA; LIMA; FARIAS, 2020). Com esse foco e com as ferramentas disponíveis, muitos profissionais têm estudado e oferecido atividades e práticas, ainda que de forma remota, para tentar minimizar os efeitos nocivos à saúde física e mental, provocados, principalmente, pelo isolamento social (OLIVEIRA; LIMA; FARIAS, 2020).

\section{A dança}

Dançar é uma prática social presente nas diversas culturas, desde as mais antigas. A dança acompanha a história da humanidade, sendo uma forma de linguagem não verbal, expressando as emoções humanas (ARDILA OSORIO, 2015; BATISTA et al., 2015; DIAZ; GURGEL; REPPOLD, 2015).

A dança pode ser entendida como um termo que permite múltiplas configurações, como manifestação artística, cerimonial, de lazer, educacional, de confraternização, comunicação, terapia e exercício, dentre outras possibilidades (BATISTA et al., 2015; MYIABARA, 2013; OLIVEIRA, 2020).
A prática regular da dança envolve muito mais do que aprender uma coreografia ou decorar e executar uma série de movimentos. Aos praticantes, a dança traz diversos benefícios sociais, psicológicos e cognitivos (BRITO; RODRIGUES NETO; SILVA, 2021; OLIVEIRA et al., 2020). O ensino e prática da dança pode ser uma oportunidade na formação de identidades individuais e de grupos sociais (GUIMARÃES; BIANCHINI, 2020).

Como prática corporal, a dança promove o desenvolvimento das capacidades funcionais, como a força muscular, a resistência aeróbica, a coordenação motora e o equilíbrio (GAJEWSKI; FALKENSTEIN, 2016; MUIÑOS; BALLESTEROS, 2018), além de contribuir para a manutenção da massa óssea e reduzir os efeitos adversos do processo de envelhecimento (BRITO; RODRIGUES NETO; SILVA, 2021). Dançar contribui também para a melhora da qualidade de vida, autoimagem corporal e autoconfiança (ARDILA OSORIO, 2015; OLIVEIRA et al., 2020).

Mais recentemente muitos pesquisadores têm se dedicado ao estudo da dança e sua relação com ganhos cognitivos, como aprendizagem, memória, concentração e atenção (DIAZ; GURGEL; REPPOLD, 2015; GAJEWSKI; FALKENSTEIN, 2016; MUIÑOS; BALLESTEROS, 2018).

$\mathrm{O}$ ato de dançar proporciona um encontro do dançarino consigo mesmo, com o aprendizado em lidar com os limites e possibilidades do movimento do seu corpo, com a magia de se comunicar sem nada falar, com a simples satisfação de dançar, se encontrar e se encantar.

\section{As mulheres que dançam}

O grupo de dança "Mulheres que dançam" (MQD) existe há mais de 15 anos, e suas participantes estão, em sua maioria, no chamado grupo da meia idade. As atividades de dança tiveram início por iniciativa do departamento de educação física de um colégio da rede privada na cidade de Campinas/SP, que disponibilizava aulas extracurriculares para alunos e pais, em várias modalidades de práticas corporais. Várias dessas mulheres (na época, mães de alunos), em sua maioria sem experiência prévia com a dança, faziam as aulas e se apresentavam em eventos do colégio, especialmente no festival de dança no final do ano, e também em apresentações diversas na cidade de Campinas e região.

Com o tempo, os filhos foram crescendo e se formando e não era mais possível participar das aulas de dança, pois era uma atividade permitida somente às mães de alunos do colégio. Assim, surgiu a ideia de manter um grupo independente com aulas com uma das professoras que atuava no projeto. O grupo se manteve e desde então faz apresentações em diversos eventos e locais, como teatros e ginásios.

As integrantes do grupo vivenciaram o adoecimento de algumas colegas, bem como de familiares, e a eventual perda de pessoas queridas. O grupo precisou se reinventar para superar os desafios para se manter como grupo e utilizar o relacionamento como suporte nesse período difícil. Foram propostas várias atividades, em sua maioria, relacionadas à dança, visando reduzir os impactos físicos e psicológicos causados pelo isolamento social.

O objetivo deste artigo é relatar a experiência vivenciada por um grupo de dança composto por mulheres na 
meia idade, que realizou diversas atividades para manter-se como grupo de dança, e atenuar os efeitos negativos da pandemia.

\section{MÉTODOS}

O grupo tem a participação de 22 pessoas. Durante a pandemia algumas se afastaram, ou já estavam afastadas em função de outros compromissos. Participaram das atividades propostas durante $\mathrm{o}$ isolamento social entre março e dezembro de 2020, 17 mulheres. Foi utilizado um breve questionário com perguntas abertas e fechadas, enviado via e-mail para que as participantes pudessem informar em que atividades participaram e fazer um breve relato sobre como foi participar dessas atividades. Das 17 mulheres que participaram, 16 responderam ao questionário. Além do questionário, as mulheres expuseram suas impressões sobre as atividades durante os horários de bate-papo do grupo, que acontecia em um dos horários de aula na semana. Todas as participantes concordaram em participar das atividades realizadas e também com a elaboração deste relato.

\section{As atividades realizadas durante a pandemia}

A ideia nasceu da intenção em manter as alunas em atividade no período de quarentena e acabaram se tornando uma marca do grupo nesse tempo. As atividades eram apresentadas como um convite e nunca houve pressão ou imposição para que as alunas participassem. As atividades realizadas no período de isolamento estão descritas abaixo.

1) A primeira atividade proposta foi o desafio de escolher uma coreografia do jogo interativo Just Dance, no próprio jogo, ou nos vídeos disponibilizados na plataforma Youtube. A proposta era se filmar dançando uma coreografia de sua escolha e enviar ao grupo.

2) Na segunda atividade a professora disponibilizou uma figura com o título "Soletre seu nome" - desafio que se tornou bastante popular na internet, especialmente no período de isolamento social. Cada letra corresponde à execução de um número de repetições de determinado exercício, onde cada integrante teria que "soletrar" o seu nome com os exercícios correspondentes a cada letra, sem abreviações. O desafio era gravar o vídeo cumprindo esse desafio e enviar ao grupo. As que tinham nomes mais extensos tiveram que fazer mais esforço. Os vídeos eram disponibilizados no grupo, sempre com muitos comentários.

3) O terceiro desafio foi criar uma pequena sequência coreográfica em um trecho da música "Unchain My heart", interpretada por Joe Colker. A professora iniciou a sequência e ao final, no vídeo, ela desafiou uma das alunas a continuar a sequência iniciada por ela. A pessoa desafiada poderia aceitar ou passar o desafio. Se aceitasse, deveria criar uma breve sequência coreográfica e desafiar outra integrante a continuar. E assim foi até o prazo estabelecido para a realização dessa atividade. Depois que todas enviaram os seus vídeos, a professora fez a edição.

4) O quarto desafio foi fazer um vídeo com uma sequência de movimentos devidamente explicados anteriormente, que foram: colocar a máscara (de proteção, usada durante a pandemia); retirar a máscara; uma pequena sequência livre de movimentos, aplausos e um brinde com a taça personalizada com o logo do grupo. Tudo isso cada uma fez separadamente, em sua casa, e depois a professora editou em vídeo.

5) Durante o período de fechamento das escolas de dança as aulas aconteceram no formato online. Para auxiliar as alunas, a professora fazia vídeos curtos em casa com pequenos trechos da coreografia que estava sendo ensaiada. Em um desses vídeos, casualmente, ela se filmou contra a luz, tendo uma cortina fechada atrás de si. Uma das integrantes observou que o efeito tinha ficado bonito, com o corpo dançando com aquele fundo naquela saturação de luz. A professora pensou, então, em lançar um desafio para a criação e realização de uma sequência de movimentos num espaço com pouca luz, uma penumbra, mas com foco mais iluminado atrás. A música escolhida e sugerida pela professora foi Hallelujah, interpretada pelo grupo vocal Pentatonix. Os vídeos foram enviados e, ao final, a professora editou em vídeo final intitulado Nuances.

6) Festa junina online com amigo secreto junino e quadrilha virtual. Essa atividade foi, de longe, a mais esperada. Todos os anos o grupo realiza uma festa junina muito animada, com todas vestidas à caráter, com muitas brincadeiras e quitutes juninos. Nesse ano, com o isolamento social, resolveu-se fazer a brincadeira do "Amigo secreto junino", onde cada uma faria ou compraria uma comida típica de festa junina e faria chegar na sua amiga secreta. Para essa brincadeira utilizou-se um site, que realiza o sorteio e traz opções de bilhetinhos, recados, fotos, pedido de ajuda para saber o que cada uma quer ganhar, entre outras ferramentas. Cada uma usou de criatividade para entregar o seu quitute junino na casa da amiga secreta, sem ser descoberta. Para isso, foi combinado de avisar aos familiares para atenderem à porta, ou buscarem o presente na portaria do condomínio. Algumas contrataram motoboy, outras enviaram algum familiar, devidamente disfarçado, para não estragar a surpresa. De certa forma, todas as famílias foram envolvidas. Depois, todas puderam rir bastante com as histórias que cada uma viveu na entrega das comidas. No mesmo dia da entrega, à noite, foi realizada uma reunião online, com todas vestidas em trajes típicos de festa junina e cada uma tinha em mãos o seu presente que foi entregue em casa, como já descrito anteriormente. Aconteceu então a revelação do Amigo Secreto e todas puderam mostrar os seus quitutes e demonstrar o carinho envolvido em todo o processo dessa brincadeira. Muitos desses quitutes juninos oferecidos na brincadeira do Amigo Secreto foram comprados, e outros foram as próprias alunas que prepararam. A troca de receitas depois, foi inevitável. Ao final, foi realizada uma quadrilha virtual, com cada uma em sua casa. Na página da plataforma utilizada para a participação remota de todas na festa virtual, apareciam todas dançando juntas. Estava planejado também o Bingo Virtual, mas não foi possível em função do tempo. Essa atividade foi realizada posteriormente, como explicado no item 8.

7) Forrozinho - Todas foram desafiadas a gravar uma pequena sequência de dança junina, com a música que foi enviada pela professora anteriormente. Depois foi tudo reunido num vídeo: as sequências de dança junina enviadas e também a imagem de todas dançando na quadrilha virtual.

8) Bingo virtual- foi utilizado um site para a realização do Bingo Virtual, valendo uma pizza grande, entregue em casa, para a $1^{\text {a }}$ colocada. Houve uma reunião inicial, utilizando uma plataforma que possibilitasse a participação de todas, para a combinação das regras e entendimento de como funciona o Bingo Virtual. Houve registro das fotos do jogo em si e também da entrega da pizza na casa da vencedora do Bingo.

9) Cada um no seu quadrado - Uma brincadeira semelhante ao programa de humor de mesmo nome, criado durante a pandemia e veiculado pela Globo Play. Foi uma forma de interagir com o grupo de um jeito descontraído num momento tenso. Foram várias possibilidades de participação com jogos do tipo Stop, completar frases, adivinhar qual é o personagem e outras brincadeiras. Em algumas dessas atividades certas 
participantes saiam temporariamente da reunião online e voltavam depois de determinado tempo para participar, adivinhando qual seria o personagem escolhido pelas outras, por exemplo.

10) Coreografia Fragmentos - A partir do resultado do desafio de criar uma curta sequência coreográfica, descrito na atividade 3, a professora de dança do grupo resolveu montar uma coreografia, que foi intitulada de Fragmentos, utilizando essas breves sequências criadas e dançadas pelas alunas. Nessa coreografia, cada integrante do grupo que enviou sua sequência de dança, aparece com um certo destaque, seja fazendo parte da sequência em solo, ou em posição especial no palco ou ambos. Uma coreografia montada com muita criatividade, com participação de todas, seja como dançarinas e/ou como coreógrafas. Essa coreografia está no repertório de apresentação do grupo MQD para os anos seguintes.

11) Coreografias trabalhadas em modelo híbrido e gravações - antes da pandemia, o grupo estava trabalhando, presencialmente, a coreografia Spotlight, com a música de mesmo nome interpretada por Jennifer Hudson, e que continuou a ser trabalhada nas aulas online. Com a reabertura parcial das escolas de dança, a professora retornou com as aulas, em pequenos grupos que se revezavam e com o cumprimento de todo o protocolo sanitário exigido pelas autoridades locais. A coreografia continuou a ser trabalhada presencialmente. A outra coreografia, a Fragmentos (item 10), se iniciou nas au las online e continuou a ser trabalhada no retorno presencial. Assim, foram desenvolvidas e trabalhadas duas coreografias ao longo do ano, tanto em formato presencial, como remoto. Com a impossibilidade de apresentações em palcos, por conta da aglomeração de pessoas, foi desenvolvido um projeto onde as coreografias foram filmadas por uma empresa especializada em produções de vídeos. A gravação foi realizada em ambiente amplo e arejado, com todos os protocolos de segurança vigentes na época, inclusive todos os participantes com máscaras durante todo o tempo, incluindo a performance das coreografias. Depois da edição o vídeo foi disponibilizado na página do Instagram do grupo, possibilitando que outras pessoas possam assistir ao trabalho de repertório produzido em 2020 pelo grupo MQD. Inicialmente outros grupos parceiros se uniriam no projeto e seria organizada uma apresentação no Drive-In de uma cidade vizinha, para os amigos e familiares, mas os custos mais elevados limitaram essa ação. Porém, a produção do vídeo com o repertório trabalhado nesse período de aulas remotas é um fato.

12) MQD em cena - Para o final do ano de 2020, foi planejado um encontro que, inicialmente seria presencial, em local aberto e com todos os protocolos de segurança, para assistirem ao vídeo com as duas coreografias produzidas em 2020, em meio à pandemia, e também a outras coreografias apresentadas pelo grupo em outros anos. Mas, em virtude do retorno à fase amarela do Plano São Paulo em todo o estado e, consequentemente, o endurecimento nas medidas de controle da pandemia, foi um encontro virtual. Houve muitas mudanças no planejamento, mas ao final, decidiu-se por entregar um kit individual de festa a cada participante do grupo, em um esquema drive-thru em um local amplo e seguro. Cada uma recebeu o seu kit festa e mais tarde aconteceu um encontro virtual, com comidas gostosas, papo animado, brincadeiras e muita gratidão. Todas receberam, nesse mesmo dia, o link do vídeo com as coreografias que foram gravadas. Essa foi a forma encontrada, dentro das restrições vigentes, de encerrar bem e de jeito festivo, um ano que foi tão diferente para todos.

\section{RESULTADOS E DISCUSSÃo}

Das 17 mulheres que participaram das atividades do grupo MQD em 2020, 16 responderam ao questionário.
Com relação à faixa etária das participantes, a idade varia entre 31 e 60 anos, sendo a média de idade de 52,25 anos. A que tem 31 anos é filha de uma outra integrante e está no grupo desde 2009. Ela resolveu participar por iniciativa própria e declara "Amo a energia e união do grupo".

Quanto à participação nas atividades, 11 mulheres $(68,75 \%)$ participaram de quase todas as atividades. Apenas duas mulheres $(12,5 \%)$ participaram de todas as atividades realizadas. Três (18,75\%) participaram de 5 atividades dentre as 12 sugeridas. Esses resultados demonstram o bom engajamento do grupo nas diversas atividades que aconteceram durante o isolamento social.

No questionário havia uma pergunta sobre quais seriam as três atividades preferidas por cada integrante. Como resultado, as quatro atividades mais indicadas como prediletas pelas participantes foram as atividades 5, 11, 4 e 6. O Quadro 1 traz trechos dos relatos das participantes sobre a participação nas atividades.

Ao passo em que as participantes foram se envolvendo nos desafios, começou a se desenhar um projeto de trabalho durante a pandemia, em 2020, totalizando 12 diferentes atividades individuais e em grupo. A intenção foi utilizar a dança e outras atividades para trabalhar a criatividade, a imaginação, as habilidades singulares de cada uma e a linguagem por meio do movimento, além da interação social do grupo.

A pandemia alterou a rotina de prática de exercícios físicos das pessoas de forma geral. Até a permanência em locais públicos como praias, parques e praças, foi proibido em algumas cidades. Embora tratando-se de uma medida estratégica para a contenção do contágio, o isolamento social, muitas vezes restrito apenas à residência, pode diminuir a interação social e impactar na motivação para o exercício e na relação que a pessoa tem com o movimento, até porque muitas práticas corporais são dependentes de uma estrutura mínima de espaço e equipamentos (BARREIRA; TELLES, FILGUEIRAS, 2020; BRITO; RODRIGUES NETO; SILVA, 2021; MARSON, 2021). O isolamento social pode trazer consequências negativas, como o aumento da inatividade física, a diminuição dos contatos sociais, o aumento do estresse, da ansiedade e outros problemas de origem psicológica (BRITO; RODRIGUES NETO; SILVA, 2021). De certa forma, todos esses fatores estavam presentes no grupo e precisavam ser trabalhados.

Algumas pesquisas demonstraram que a prática de exercícios físicos pode ser uma boa medida para o enfrentamento à pandemia (MARSON, 2021). Uma das razões é porque a prática regular e em intensidade apropriada melhora a competência do sistema imunológico. É sabido também que o exercício físico, em condições adequadas, pode auxiliar na prevenção e combate ao sobrepeso e obesidade, além de melhorar a aptidão física e cardiorrespiratória, reduzir a inflamação sistêmica e de estados pró trombóticos, diminuir o estresse oxidativo, melhorar o metabolismo da glicose, insulina e lipídeos (MARSON, 2021; SILVEIRA et al., 2020). Possivelmente também favorece a resposta do organismo à vacina (SILVEIRA et al., 2020). Segundo Costa (2021) outra razão apontada para a importância da atividade física no contexto da pandemia é a melhor evolução dos quadros graves de COVID-19, possivelmente associada à produção de substâncias anti-inflamatórias como consequência da prática de exercícios. 
Quadro 1. Trechos de relatos das participantes.

\begin{tabular}{|c|c|}
\hline Part. ${ }^{1}$ & Relatos \\
\hline 1 & $\begin{array}{l}\text { "Gostei de tudo. Foi uma forma de distração e de se exercitar. } \\
\text { Só não gostava dos encontros pra bate-papo, pois já trabalha- } \\
\text { va online o dia todo e ficar conectada pra conversar pra mim } \\
\text { era cansativo". }\end{array}$ \\
\hline 2 & $\begin{array}{l}\text { "Foi uma experiência muito boa, não tive dificuldade de par- } \\
\text { ticipar. Essas atividades foram muito benéficas para o físico e } \\
\text { para o psicológico, pois proporcionou, mesmo no isolamento, } \\
\text { uma interação com todas". }\end{array}$ \\
\hline 3 & $\begin{array}{l}\text { "Achei ótimo para manter as pessoas unidas, se movimen- } \\
\text { tando e cuidando da saúde física e mental, já que estávamos } \\
\text { passando por um momento tão difícil e estressante. Adoro a } \\
\text { energia e união do grupo." }\end{array}$ \\
\hline 4 & $\begin{array}{l}\text { "Não me arrependi de participar de nenhuma, só não fiz mais } \\
\text { por falta de tempo... foi muito bom, uma distração durante a } \\
\text { pandemia". }\end{array}$ \\
\hline 5 & $\begin{array}{l}\text { Foi extremamente importante este trabalho da professora. } \\
\text { Me ajudou a manter meu equilíbrio emocional e minha ativi- } \\
\text { dade física e, mesmo à distância, mantivemos nosso convívio } \\
\text { social. Este grupo é muito unido e divertido. }\end{array}$ \\
\hline 6 & $\begin{array}{l}\text { Amei fazer todas as atividades. Foi super válido. Nossa profes- } \\
\text { sora foi excelente, se preocupou todo momento conosco para } \\
\text { que não ficássemos paradas, desanimadas e desconectadas. }\end{array}$ \\
\hline 7 & $\begin{array}{l}\text { Para mim nenhuma aula remota substitui o que temos nas } \\
\text { aulas presenciais, porém, me manter conectada com este gru- } \\
\text { po e participar das atividades propostas foi muito importante } \\
\text { para o meu equilíbrio emocional. }\end{array}$ \\
\hline 8 & $\begin{array}{l}\text { Eu comecei fazendo as atividades e gostando bastante, mas } \\
\text { logo depois, talvez pela menor movimentação durante a pan- } \\
\text { demia, as minhas "ites" começaram a atacar e os movimentos } \\
\text { ficaram limitados e isso me impossibilitou de continuar. }\end{array}$ \\
\hline 9 & $\begin{array}{l}\text { “Foi mágico! Estar com as amigas e com a nossa querida pro- } \\
\text { fessora, que em nenhum momento desistiu das MQD, com } \\
\text { certeza fez a diferença nesse momento de isolamento. }\end{array}$ \\
\hline 10 & $\begin{array}{l}\text { "Gostei de tudo, mas não dei conta de participar de todas. De } \\
\text { início eu conseguia participar mais das atividades, este ano } \\
\text { foi difícil para todo mundo, mas como continuo trabalhando } \\
\text { e na área da saúde, de forma presencial, foi bem intenso, por } \\
\text { vezes não conseguia participar das atividades propostas". }\end{array}$ \\
\hline 11 & $\begin{array}{l}\text { "No começo fiquei em dúvida, mas depois fui gostando, } \\
\text { apesar de sentir um pouco de dificuldade em realizar alguns } \\
\text { movimentos propostos pela professora, foram momentos de } \\
\text { descontração e relaxamento". }\end{array}$ \\
\hline 12 & $\begin{array}{l}\text { "A pandemia me desmotivou a interagir com as atividades } \\
\text { online. Gosto do presencial, da conversa, do abraço, dos } \\
\text { sorrisos, da troca mútua. E tenho muita dificuldade em ter } \\
\text { disciplina fora da sala de aula. }\end{array}$ \\
\hline 13 & $\begin{array}{l}\text { "As atividades propostas pela professora foram muito impor- } \\
\text { tantes naquele momento para nos movimentar fisicamente, } \\
\text { nos preencher emocionalmente com atividades divertidas e } \\
\text { nos manter em contato durante todo o tempo. Isso foi um } \\
\text { grande diferencial nesse tempo tão difícil e tão triste". }\end{array}$ \\
\hline 14 & $\begin{array}{l}\text { "Foi energizante, poder compartilhar de notícias pessoais, de } \\
\text { cada uma, divertir-se, trabalho esse realizado pela professora, } \\
\text { essa incansável pessoa". }\end{array}$ \\
\hline 15 & $\begin{array}{l}\text { As atividades virtuais foram sempre motivadoras e criativas } \\
\text { e deixavam a semana com um clima menos tenso. Foi muito } \\
\text { bom se sentir desafiada em produzir as tarefas usando o es- } \\
\text { paço da nossa casa, usando a tecnologia e buscando o nosso } \\
\text { melhor nos movimentos. }\end{array}$ \\
\hline 16 & $\begin{array}{l}\text { "Foi uma terapia pra mim, todas as atividades me ajudaram } \\
\text { muito durante a pandemia. É um grupo muito dinâmico, nos } \\
\text { conhecemos há muitos anos e por isso já fazem parte da } \\
\text { minha família". }\end{array}$ \\
\hline
\end{tabular}

Fonte: Os autores.

Assim, tem sido aconselhado, durante e após a pandemia, que além dos cuidados de higiene, mantenha-se um estilo de vida saudável, minimizando fatores estressores e que se fortaleça o sistema imune (SILVEIRA et al., 2020). É importante para os indivíduos permanecerem fisicamente ativos, mesmo estando socialmente distanciados (MARSON, 2021).
Como foi abordado, a pandemia trouxe restrições à prática de atividade física, mas as pesquisas demonstram a importância de se permanecer ativo fisicamente também nesse período. Felizmente há muitas opções de práticas de exercícios, mas é necessária maior motivação para toda essa mudança de rotina. Nesse sentido, as atividades do grupo MQD durante a pandemia foram importantes, por promover a dança e exercícios durante o isolamento.

A dança tem uma peculiaridade em sua prática, pois trabalha a cooperação entre os participantes. Essa característica faz com que não apenas a capacidade física e as habilidades motoras sejam desenvolvidas, mas também as funções psíquicas (BRANCO, 2011). Além das alterações fisiológicas, a dança proporciona alterações positivas no âmbito social e psicológico, colaborando para uma boa qualidade de vida (OLIVEIRA et al., 2020). Também por estimular a responsabilidade e o senso de competência, a dança pode melhorar a autoestima, o autoconceito e a percepção de bem-estar, além de ser benéfica no combate ao estresse e ser importante em casos de prevenção e tratamento de casos clínicos de depressão (BRANCO, 2011; OLIVEIRA et al., 2020). Por isso, a dança é uma ferramenta tão importante em todo o tempo, especialmente durante a necessidade de isolamento social.

Fazer as aulas no formato online não tem o mesmo dinamismo, interação e motivação de uma aula presencial. Além disso os cômodos das casas viraram salas de dança de forma improvisada, com piso inadequado e frio, móveis e objetos por todo lugar, mas foi o melhor a ser feito na situação por tantos profissionais e praticantes da dança (FELTES et al., 2021; LESSA, 2020).

Apesar das dificuldades enfrentadas, pode-se inferir que esse foi um ano muito produtivo e de muita proximidade entre as integrantes do grupo, apesar de distantes fisicamente. Todas relataram, no questionário e nos encontros virtuais, que aprenderam muito juntas, ainda que separadas. Pelos relatos, pode-se inferir que foi algo muito interessante para manter o relacionamento social e a saúde mental, que tanto afetou e tem afetado as pessoas de maneira geral, em especial, as mulheres (FILGUEIRAS; STULTS-KOLEHMAINEN, 2020). Parece que o decréscimo na saúde aparece de forma mais pronunciada entre as pessoas com menor suporte social, sendo as mulheres mais afetadas que os homens. O suporte social também é um bom mediador para o estresse (BRANCO, 2011), por isso é tão importante serem mantidas as oportunidades de contato e interação, ainda que de forma virtual.

Ainda considerando o suporte social, a Fundação Oswaldo Cruz preparou algumas orientações gerais de estratégias para o enfrentamento à pandemia, visando a saúde mental. A recomendação é manter ativa a rede socioeducativa, estabelecendo-se o contato com familiares, amigos e colegas, ainda que de forma virtual (FIOCRUZ, 2020). Essa foi uma grande preocupação para o grupo MQD: manter os relacionamentos, especialmente nesse período de tensão, para tornar mais leve essa experiência, e isso fortaleceu ainda mais a identidade do grupo.

Ao final, percebeu-se que muito foi realizado. De certa, forma, talvez até mais do que se fosse um ano "normal". Inclusive duas coreografias foram trabalhadas em um modelo híbrido (nas aulas presenciais e online) e finalizadas. Diante da impossibilidade de apresentação nos teatros e 
outros espaços públicos, essas coreografias foram gravadas e editadas em vídeo por uma equipe profissional e esse material será uma lembrança desse tempo tão diferente, a começar que todas dançaram com máscaras. Todos os vídeos produzidos nesse período podem ser visualizados na página do grupo no Instagram: mulheres.que.dancam. Com os resultados alcançados nessas atividades durante a pandemia, algumas que estavam afastadas das atividades de dança do grupo, retornaram.

\section{CONCLUSÃO}

As medidas de diferentes níveis de restrição social para reduzir o alastramento do contágio da COVID-19, como a quarentena, o afastamento, o isolamento, e até o lockdown, afetam diretamente, em maior ou menor grau, os modos usuais com que as pessoas se movimentam corporalmente, individualmente ou coletivamente. Isso implica em perdas na qualidade de movimento, na qualidade de vida e na saúde mental (BARREIRA; TELLES, FILGUEIRAS, 2020).

No ano de 2020 o grupo MQD tinha muitos planos e foi surpreendido com a pandemia da COVID-19. Inicialmente pensou-se que seria um tempo mais curto de isolamento social e a preocupação era manter o relacionamento entre as integrantes do grupo. Com o tempo, além do encontro semanal para a conversa e diversão juntas, iniciaram-se as aulas de dança em formato online, o que não é trivial. Problemas com a conexão da internet, imagens que travam, música que não sincroniza com a imagem, dificuldade em ensinar alguns movimentos e sequências, que são difíceis de visualizar na tela.

O isolamento social trouxe, para muitos, uma frequência menor na prática de atividades físicas, assim como menor intensidade nessas atividades (BRITO; RODRIGUES NETO; SILVA, 2021). Também sentimentos de tristeza pela falta de contato presencial com amigos e familiares e até depressão têm sido relatados. Além disso, as mulheres parecem sentir um maior impacto psicológico pela quarentena em relação aos homens (BARROS; GRACIE, 2020). As atividades realizadas pelo grupo MQD foram oferecidas com o objetivo de manter essas mulheres com alguma prática de atividades físicas e também com envolvimento social prazeroso, ainda que à distância, de forma a minimizar os efeitos adversos do isolamento social, e, pelos resultados alcançados, considera-se que o objetivo foi alcançado. Espera-se que esse relato sirva como estímulo a outros grupos de dança, que, assim como o grupo MQD, precisam se reinventar e enfrentar as dificuldades para se manterem atuantes e relevantes, no próprio grupo e na sociedade em qualquer tempo, especialmente numa pandemia.

\section{AGRADECIMENTOS}

As autoras agradecem às integrantes do grupo MQD, por terem respondido ao questionário, compartilhando suas experiências e emoções e por terem autorizado a publicação deste relato.

\section{CONFLITO DE INTERESSE}

Os autores do estudo declaram não haver conflito de interesses.

\section{FINANCIAMENTO}

Este estudo não teve apoio financeiro.

\section{REFERÊNCIAS}

ARDILA OSORIO, G. P. Possibilidades e limites da dança para o empoderamento das mulheres: um olhar da saúde coletiva. 2015. 128f. Dissertação (Mestrado em Medicina Preventiva) - Universidade de São Paulo, São Paulo. Disponível em: https://www.teses.usp.br/teses/disponiveis/5/5137/ tde-26102015-153202/publico/GinaPaolaArdilaOsorioVersaoCorrigida.pdf.

BARREIRA, C. R. A.; TELLES, T. C. B.; FILGUEIRAS, A. Perspectivas em psicologia do esporte e saúde mental sob a pandemia de covid-19. Psicologia: Ciência e Profissão, Brasília, v. 40, e243726, 1-14, 2020. Disponível em: https://www.scielo.br/pdf/pcp/v40/1982-3703-pcp-40-e243726.pdf.

BARROS, M. B. A: GRACIE, R. Relato de tristeza/depressão, nervosismo/ ansiedade e problemas de sono na população adulta brasileira durante a pandemia de COVID-19. Epidemiologia e Serviços de Saúde, Brasília, v. 29, n. 4, 24 2020. Disponível em: https://www.scielosp.org/article/ress/2020. v29n4/e2020427/pt/.

BATISTA, N. N. L. A. L.; MONTE, R. S. LIMA, S. C. S. MARINHO, A. R. L. MOITA, D. K. L. S.; LIMA, L. O. M. Trabalhando a educação popular em saúde com a dança. Revista Eletrônica Gestão \& Saúde, Brasília, v. 6. Supl. 1, p. 81723, 2015, Disponível em: https://periodicos.unb.br/index.php/rgs/article/ view/2726/2435.

BRANCO, S. M. L. A senhora dança? Um estudo exploratório da influência da dança no suporte social e no bem-estar Psicológico em Adultos Portugueses. 2011. ??f. Dissertação (Mestrado em Psicologia Clínica) - Instituto Superior Miguel Torga, Coimbra, 2011. Disponível em: https://www.psicologia.pt/teses/textos/TE0008.pdf.

BRITO, B.; RODRIGUES NETO, G.; SILVA, J. Qualidade de vida de praticantes de dança em academias no período pandêmico da covid-19. Revista de Ciências da Saúde Nova Esperança, Cidade, v. 19, n. 1, p. 24-30, 2021. Disponível em: https://revista.facene.com.br/index.php/revistane/article/ view/680/453.

COSTA, R. F. A atividade física pode ajudar na luta contra a CoViD-19? Journal of Physical Education, Maringá, v. 89, n. 4, p. 224-227, 2021. DOI: http:// dx.doi.org/10.37310/ref.v89i4.2720.

DIAZ, G. B.; GURGEL, L.G.; REPPOLD, C. T. Influência da dança na memória e atenção: uma revisão sistemática da literatura. Ciência e Movimento, Porto Alegre, v. 17, n. 35, p. 29-37, 2015. Disponível em: https://www.metodista. br/revistas/revistas-ipa/index.php/RS/article/view/264/273.

FELTES, A. F.; PACHECO, D. S.; HERRMANN, J. C.; PINTO, A. S. Re-significando a prática docente em tempos de pandemia: transformando casas em salas de aula de dança. Revista da Fundarte, Montenegro, v. 21, n. 44, p. 1-18, 2021. Disponível em: http://.seer.fundarte.rs.gov.br/index.php/revistadafundarte/index.

FILGUEIRAS, A.; STULTS-KOLEHMAINEN. The relationship between behavioural and psychosocial factors among brazilians in quarantine due to Covid-19. The Lancet Psychiatry, London, v.3, n.31, p. 1-17, 2020. Disponível em: https://papers.ssrn.com/sol3/papers.cfm?abstract_id=3566245.

FIOCRUZ. Fundação Oswaldo Cruz. Saúde mental e atenção psicossocial na pandemia de Covid- 19. Disponível em: https://portal.fiocruz.br/documento/saude-mental-e-atencao-psicossocial-na-pandemia-covid-19. Acessado em: 05 de novembro de 2020

GUIMARÃES, J. R.; BIANCHINI, H. M. Dança: um conteúdo desafiador. Caderno de Educação Física e Esporte, Marechal Cândido Rondon, v. 18, n. 1, p. 55-60, 2020. DOI: https://doi.org/10.36453/2318-5104.2020.v18.n1.p55.

GAJEWSKI, P. D.; FALKENSTEIN, M. Physical activity and neurocognitive functioning in aging - a condensed updated review. European Review of Aging and Physical Activity, Hidelberg, v. 13, n. 1, p. 1-7, 2016. DOI: http://dx.doi. org/10.1186/s11556-016-0161-3.

LESSA, H. T. Aulas de dança em tempos de pandemia: (oscil)ações de uma professora-artista. Incomum - Revista de Arte, Educação, Profissionalização e Comunidades, Goiânia, v. 1, n. 2, p. 1-18, 2020. Disponível em: http:// revistas.ifg.edu.br/incomum/article/view/872. Acessado em: 20 de dezembro de 2020.

MARSON, R. A. Atividade física e CoViD-19 - implicações biopsicofisiológicas: uma resenha do artigo de revisão de Woods et al. Journal of Physical Education, Maringá, v. 89, n. 4, p. 251-4, 2021. DOI: http://dx.doi.org/10.37310/ ref.v89i4.2725.

MIYABRA, R. A dança como linguagem corporal. Revista Santa Rita, São Paulo, v. 8, n. 16, , p. 34-8, 2013. Disponível em: https://www.researchgate.net/profile/Fernando Almeida-Santos/publication/331210332 Atividades de Controladoria em uma Rede de Estacionamentos/ links/5c6c48d94585156b570a8d79/Atividades-de-Controladoria-em-uma-Rede-de-Estacionamentos.pdf\#page=34. Acesso em: 04 out. 2020.

OLIVEIRA, F. P.; LIMA, M. R. S.; FARIAS, F. L. R. Terapias integrativas e com- 
plementares em situações emocionais na pandemia do COVID-19. Revista Interdisciplinar, Teresina, v. 13, n. 1, p. 1-8, 2020. Disponível em: https:// revistainterdisciplinar.uninovafapi.edu.br/index.php/revinter/article/ view/1778/0

MUIÑOS, M. BALLESTEROS, S. Does physical exercise improve perceptual skills and visuospatial attention in older adults? A review. European Review of Aging and Physical Activity, Hidelberg, v. 15, n. 2, p. 1-12, 2018. Disponível em: https://eurapa.biomedcentral.com/track/pdf/10.1186/s11556-0180191-0.pdf.

OLIVEIRA, M. P. S · SANTOS, E. V · RODRIGUES, M. R. S · SILVA, L A. Dança saúde: discutindo sobre os principais benefícios da dança nos aspectos psicológicos em mulheres. Revista de Educação, Saúde e Ciências do Xingu, Belém, v. 1, n. 2, p. 35-43, 2020. Disponível em: https://core.ac.uk/downlo$\mathrm{ad} / \mathrm{pdf} / 288212877 . \mathrm{pdf}$.

OPAS. Organização Pan-Americana da Saúde. OMS afirma que COVID-19 é agora caracterizada como pandemia. OPAS Brasil. Disponível em: https://www. paho.org/bra/index.php?option=com content\&view=article\&id=6120:oms-afirma-que-covid-19-e-agora-caracterizada-como-pande- mia\&ltemid=812. Acessado em: 07 de julho de 2020 .

SILVEIRA, M. P.; SILVA FAGUNDES, K. K.; BIZUTTI, M. R.; STARCK, E.; ROSSI, R. C.; RESENDE E SILVA, D. T. Physical exercise as a tool to help the immune system against COVID-19: an integrative review of the current literature. Clinical and Experimental Medicine (Online), Nova York, n. 21, n. 1, p. 15 28, 2020. Disponível em: https://link.springer.com/content/pdf/10.1007/ s10238-020-00650-3.pdf. Acessado em: 26 de junho de 2021

\section{ORCID E E-MAIL DOS AUTORES}

Elida Fogliarini Capelatto

(iD) https://orcid.org/0000-0002-0758-9829

@ fafelida@gmail.com

Rosane Beltrão da Cunha Carvalho (Autor Correspondente)

(iD) https://orcid.org/0000-0001-7398-0503

@ robeltraoccarvalho@gmail.com 